\title{
Indole-3-carbinol regulates microglia homeostasis and protects the retina from degeneration
}

\author{
Amir Saeed Khan ${ }^{1}$ and Thomas Langmann ${ }^{1,2^{*}}$ (D)
}

\begin{abstract}
Background: Retinal degenerative diseases significantly contribute to visual impairment and blindness. Microglia reactivity is a hallmark of neurodegenerative diseases including retinal cell death and immunomodulation emerges as a therapeutic option. Indole-3-carbinol (I3C) is a natural ligand of aryl hydrocarbon receptor (AhR), with potent immunomodulatory properties. Here, we hypothesized that I3C may inhibit microglia reactivity and exert neuroprotective effects in the light-damaged murine retina mimicking important immunological aspects of retinal degeneration.
\end{abstract}

Methods: BV-2 microglia were treated in vitro with I3C followed by lipopolysaccharide (LPS) stimulation to analyze pro-inflammatory and anti-oxidant responses by quantitative real-time PCR (qRT-PCR) and Western blots. Nitric oxide (NO) secretion, caspase 3/7 levels, phagocytosis rates, migration, and morphology were analyzed in control and AhR knockdown cells. I3C or vehicle was systemically applied to light-treated BALB/CJ mice as an experimental model of retinal degeneration. Pro-inflammatory and anti-oxidant responses in the retina were examined by qRTPCR, ELISA, and Western blots. Immunohistochemical staining of retinal flat mounts and cryosections were performed. The retinal thickness and structure were evaluated by in vivo imaging using spectral domain-optical coherence tomography (SD-OCT).

Results: The in vitro data showed that $13 \mathrm{C}$ potently diminished LPS-induced pro-inflammatory gene expression of INOS, IL-1B, NLRP3, IL-6, and CCL2 and induced anti-oxidants gene levels of NQO1, HMOX1, and CAT1 in BV-2 cells. I3C also reduced LPS-induced NO secretion, phagocytosis, and migration as important functional microglia parameters. siRNA-mediated knockdown of AhR partially prevented the previously observed gene regulatory events. The in vivo experiments revealed that ISC treatment diminished light-damage induced I-NOS, IL-1B, NLRP3, IL-6, and CCL2 transcripts and also reduced CCL2, I-NOS, IL-1B, p-NFkBp65 protein levels in mice. Moreover, I3C increased antioxidant NQO1 and HMOX1 protein levels in light-exposed retinas. Finally, I3C therapy prevented the accumulation of amoeboid microglia in the subretinal space and protected from retinal degeneration.

Conclusions: The AhR ligand I3C potently counter-acts microgliosis and light-induced retinal damage, highlighting a potential treatment concept for retinal degeneration.

Keywords: Aryl hydrocarbon receptor, Indole-3-carbinol, Microglia, Retinal degeneration, Light damage

\footnotetext{
*Correspondence: thomas.langmann@uk-koeln.de

'Laboratory for Experimental Immunology of the Eye, Department of

Ophthalmology, Faculty of Medicine and University Hospital Cologne,

University of Cologne, Joseph-Stelzmann-Str. 9, D-50931 Cologne, Germany

${ }^{2}$ Center for Molecular Medicine Cologne, Cologne, Germany
}

(c) The Author(s). 2020 Open Access This article is licensed under a Creative Commons Attribution 4.0 International License, which permits use, sharing, adaptation, distribution and reproduction in any medium or format, as long as you give appropriate credit to the original author(s) and the source, provide a link to the Creative Commons licence, and indicate if changes were made. The images or other third party material in this article are included in the article's Creative Commons licence, unless indicated otherwise in a credit line to the material. If material is not included in the article's Creative Commons licence and your intended use is not permitted by statutory regulation or exceeds the permitted use, you will need to obtain permission directly from the copyright holder. To view a copy of this licence, visit http://creativecommons.org/licenses/by/4.0/ The Creative Commons Public Domain Dedication waiver (http://creativecommons.org/publicdomain/zero/1.0/) applies to the data made available in this article, unless otherwise stated in a credit line to the data. 


\section{Background}

Phagocytes of the retina, microglia and macrophages, have been recognized as important factors in retinal degenerative diseases. In the healthy retina, ramified microglia localize in the inner and outer plexiform layers (IPL, OPL) and scan their microenvironment with their surface receptors for cytokines, chemokines, and complement factor [1, 2]. In the diseased retina, these cells become amoeboid and migrate to subretinal (SR) space with upregulation of different pro-inflammatory molecules [2, 3]. Initially, microglia enhance their phagocytosis capacity to resolve tissue damage. However, persistent disease leads to chronically activate microglia, which may ingest not only cellular debris but also healthy photoreceptors [4]. Therefore, microglia-targeted pharmacotherapy to mitigate chronic neuro-inflammation may be a promising treatment approach in retinal degenerative diseases.

Aryl hydrocarbon receptor (AhR), a ligand-dependent transcriptional factor, is activated by various ligands [5]. Initially, AhR was identified as key regulator of xenobiotic metabolism and detoxification [6]. Inactive AhR localizes in the cytoplasm and upon binding of a ligand, the protein dissociates from chaperones and translocates into the nucleus where it binds to nuclear response element and changes gene transcription required for cellular homeostasis [6]. AhR deficiency accelerates aging in mice and triggers inflammation [7-9], and AhR ligands play an important role in immune modulation $[9,10]$.

In the ocular compartment, AhR knockout triggers apoptosis and inflammation in experimental autoimmune uveitis [11]. AhR deficiency also disturbs extracellular matrix biology, leading to an AMD-like pathology in mice [12]. Moreover, $\mathrm{AhR}^{-1-}$ mice showed a reduction in visual function, displayed an accumulation of microglia in the SR space, and had retinal pigment epithelium (RPE) abnormalities [13]. $\mathrm{AhR}^{-/-}$mice also showed larger lesions in laser-induced choroidal neovascularization that mimics the wet form of AMD [14]. Furthermore, 2,2'-aminophenyl indole (2AI), a synthetic ligand of AhR could protect the RPE and retina from environmental stress [15].

Here, we hypothesized that AhR agonists may regulate microglia homeostasis and dampen experimental neurodegeneration in the retina. To test this hypothesis, we used a naturally occurring AhR agonist, indole-3-carbinol (I3C), which is abundant in green vegetables. We addressed the effects of $\mathrm{I} 3 \mathrm{C}$ in vitro using the microglial BV-2 cell line [16] and systemically applied I3C in BALB/cJ mice exposed to an acute white-light-damage paradigm.

\section{Methods}

\section{Reagents}

I3C (I7256-5G) and Escherichia coli 0111: B4 lipopolysaccharide (LPS) were purchased from Sigma-Aldrich (St. Louis, MO, USA).

\section{Cell culture}

BV-2 microglia were seeded in RPMI640 supplemented with $5 \%$ fetal calf serum (FCS), $1 \%$ penicillin/streptomycin, $2 \mathrm{mM}$ L-glutamine and $195 \mathrm{nM} \beta$-mercaptoethanol at $37^{\circ} \mathrm{C}$ in a humidified atmosphere of $5 \% \mathrm{CO} 2$. The cells were pre-treated with $50 \mu \mathrm{M} \mathrm{I3C}$ for $4 \mathrm{~h}$ and then stimulated with $50 \mathrm{ng} / \mathrm{ml}$ LPS for $4 \mathrm{~h}$. After treatments, cells were harvested for RNA and protein extraction. Cell supernatants were also collected for further analysis. The $661 \mathrm{~W}$ photoreceptor-like cells were cultured in Dulbecco's modified Eagle's medium (DMEM) supplemented with 10\% FCS, L-glutamine, and 1\% penicillin/streptomycin.

RNA isolation, reverse transcription, and quantitative RT-PCR Total RNA was extracted from the harvested BV-2 cells using the NucleoSpin ${ }^{\bullet}$ RNA Mini Kit (Macherey-Nagel; Dueren, Germany). Total RNA was also extracted from the retinas of $\mathrm{BALB} / \mathrm{cJ}$ mice using the Qiagen RNeasy Micro Kit according to the manufacturer. RNA was quantified with a NanoDrop 2000 photometer (Thermo Scientific). First-strand complementary DNA synthesis was performed using the Thermo RevertAid RT Kit (ThermoFisher Scientific; Waltham, USA). qRT-PCR analysis was performed with the Takyon ${ }^{\text {tw }}$ qPCR Kit (Eurogentec Deutschland GmbH; Köln, Germany) and the Roche Probe library using the LightCycler ${ }^{\circ} 480$ II machine (Roche; Basel, Switzerland). Primer sequences and Roche library probe numbers were as follows: $\mathrm{i}$ NOS, forward primer $5^{\prime}$-ctttgccacggacgagac-3', reverse primer $5^{\prime}$-tcattgtactctgagggctga- 3 ', probe \#13; IL-1ß, forward primer $5^{\prime}$-tcttctttgggtattgcttgg- $3^{\prime}$, reverse primer 5 '-tgtaatgaaagacggcacacc-3', probe \#38; NLRP3, forward primer $5^{\prime}$-ttcccagacactcatgttgc- $3^{\prime}$, reverse primer 5'-agaagagaccacggcagaag-3', probe \#74; CCL2, forward primer $5^{\prime}$-catccacgtgttggctca-3', reverse primer $5^{\prime}$-gatcatcttgctggtgaatgagt-3', probe \#62; IL6, forward primer $5^{\prime}$-gatggatgctaccaaactggat-3', reverse primer $5^{\prime}$ ccaggtagctatggtactccaga-3', probe \#6; NQO1, forward primer 5'-agcgttcggtattacgatcc-3', reverse primer $5^{\prime}$ agtacaatcagggctcttctcg-3', probe \#50; HMOX1, forward primer 5'-agggtcaggtgtccagagaa-3', reverse primer 5'cttccagggccgtgtagata-3', probe \#9; CAT1, forward primer $5^{\prime}$-ccttcaagttggttaatgcaga-3', 5' -caagtttttgatgccctggt-3', probe \#34; ATPase, forward primer 5 '-ggcacaatgcaggaaagg-3', reverse primer 5 '-tcagcaggcacatagatagcc-3', probe \#77. Measurements were performed in triplicates. ATP5b expression was used as a reference gene. For relative quantification, the $\Delta \Delta \mathrm{C}$ method was used as implemented in the LightCycler 480 software.

\section{Protein extraction, ELISA, and Western blot}

RIPA buffer (150 mM sodium chloride $(\mathrm{NaCl}), 1 \% \mathrm{NP}$ $40,0.5 \%$ sodium deoxycholate, $0.1 \%$ sodium dodecyl sulfate (SDS), $50 \mathrm{mM}$ Tris- $\mathrm{HCl} \mathrm{pH} 7.4$, supplemented 
with protease inhibitor cocktail (Roche)) was used to extract cell lysates. Mouse retinal tissue was homogenized in PBS using sonication. Insoluble debris was removed by centrifugation for $15 \mathrm{~min}$ at $16,000 \times g$. Protein concentration was determined using the PierceTM Bicinchoninic Acid (BCA) Protein Assay Kit (Thermo. Scientific, Cat \#23225). Twenty micrograms of cell or tissue lysates were separated by SDS-PAGE on $10 \%$ gels with PageRuler prestained protein ladder (Thermo Scientific; Waltham, MA, USA). Proteins were then transferred to nitrocellulose membranes (Biorad; Munich, Germany). After incubation in blocking buffer (TBS-T containing 5\% nonfat dry milk) for $1 \mathrm{~h}$, membranes were incubated with primary antibodies against I-NOS (dilution 1:2000 in PBS, Cat \#610600, BD Transduction Laboratories ${ }^{\mathrm{TM}}$ ), IL-1ß (dilution 1: 200 in PBS, Cat \#B122, Santa Cruz Biotechnology), pNFkB p65 (dilution 1:500 in PBS, Cat \#sc136548, SantaCruz Biotechnology), COX2 (dilution 1:500 in PBS, Cat \#Ab1519, Abcam), NQO1 (dilution 1:500 in PBS, Cat \#sc32793, Santa Cruz Biotechnology), HMOX1 (dilution 1:1000 in PBS, Cat \#Ab137749, Abcam), and B-ACTIN (dilution 1:200 in PBS, Cat \#sc47778, Santa-Cruz Biotechnology). After washing steps, blots were incubated with secondary antibodies (dilution 1:4000 in PBS, Cat \#P0448, Dako polyclonal goat anti-rabbit, immunoglobulins/ HRP, and dilution 1:4000 in PBS, Cat \#P0447, Dako polyclonal goat anti-mouse, immunoglobulins/HRP). Enhanced chemiluminescence signals were then visualized and imaged with the Multilmage II system (Alpha Innotech; Santa Clara, CA, USA). Densitometry of bands was measured using the Image J software (NIH). The concentration of CCL2 in total retinal lysates was measured by ELISA according to the manufacturer's instructions (Mouse CCL2/JE/MCP-1 DuoSet ELISA, Cat \#DY479-05, R\&D Systems).

\section{Nitrite measurement}

Nitric oxide concentrations were determined using the Griess reagent system (Promega). Briefly, $50 \mu \mathrm{l}$ cell culture was incubated with $100 \mu \mathrm{l}$ Griess reagent in 96-well plates. After incubation for $30 \mathrm{~min}$ at room temperature, absorbance was measured at $540 \mathrm{~nm}$ on an Infinite F200 Pro plate reader (Tecan). Nitrite concentrations were calculated as described before [17].

\section{Caspase $3 / 7$ assay}

To determine microglia neurotoxicity, a culture system of $661 \mathrm{~W}$ photoreceptors cells with the microgliaconditioned medium was established. The $661 \mathrm{~W}$ photoreceptor cells were incubated for $48 \mathrm{~h}$ either in their own medium or with culture supernatants from treated BV-2 cells. The $661 \mathrm{~W}$ cells morphology was assessed by phase-contrast microscopy and cell death was determined with the Caspase-Glo ${ }^{\circ}$ 3/7 Assay (Promega GmbH; Mannheim, Germany) as previously described [17].

\section{Phagocytosis assay}

BV-2 cells were pre-treated with DMSO as vehicle, $50 \mu \mathrm{M} \mathrm{I3C}$, vehicle $+50 \mathrm{ng} / \mathrm{ml} \mathrm{LPS}$, and $50 \mathrm{ng} / \mathrm{ml} \mathrm{LPS} \mathrm{+}$ $50 \mu \mathrm{M} \mathrm{I} 3 \mathrm{C}$ for $4 \mathrm{~h}$. After treatments, $2 \mu \mathrm{l}$ latex bead solution (polystyrene microparticles, Sigma Aldrich; St. Louis, MO, USA) was added to the wells for $4 \mathrm{~h}$ to determine the influence of $\mathrm{I} 3 \mathrm{C}$ on phagocytosis. Five micrographs per well were taken using an AxioVert.A1 inverted microscope (Carl Zeiss; Germany). The phagocytic activity was determined by calculating the number of cells, which phagocytosed 10 or more latex beads.

\section{Scratch wound healing assay}

BV-2 cells were seeded in six-well plates as $80 \%$ confluent monolayers and were wounded with a sterile $200 \mu \mathrm{l}$ pipette tip. Thereafter, the cells were treated with vehicle, $50 \mu \mathrm{M}$ I3C, vehicle $+50 \mathrm{ng} / \mathrm{ml} \mathrm{LPS}$, and $50 \mathrm{ng} / \mathrm{ml}$ LPS $+50 \mu \mathrm{M}$ I3C. Migration into the open scar was documented with microphotographs taken after $8 \mathrm{~h}$ of wounding using an AxioVert.A1 inverted microscope (Carl Zeiss; Germany).

\section{Phalloidin staining}

BV-2 cells were seeded on coverslips in six-well plates. Cells were treated with vehicle, $50 \mu \mathrm{M}$ I3C, vehicle $+50 \mu \mathrm{M} \mathrm{I} 3 \mathrm{C}$, and $50 \mu \mathrm{M} \mathrm{I} 3 \mathrm{C}+50 \mathrm{ng} / \mathrm{ml}$ LPS. Thereafter, the cells were fixed, permeabilized with $0.1 \%$ Triton X-100 and F-actin was labeled using $0.1 \mu \mathrm{g} / \mathrm{ml}$ Phalloidin-TRITC (Sigma). The nuclei were stained using 4',6-diamidino-2phenylindole (DAPI), and coverslips were mounted onto slides using Dako fluorescent mounting medium (Dako Deutschland GmbH; Hamburg, Germany). Photos were taken with a Zeiss Imager M.2 equipped with Apotome.2 (Carl Zeiss; Germany).

\section{siRNA-mediated AhR gene silencing}

BV-2 cells were transfected with AhR siRNA (FlexiTube siRNA containing 4 preselected siRNAs for the AhR gene, Cat \#1027416, Qiagen; Hilden Germany) and the siRNA non-targeting negative control (Cat \#1022076, Qiagen; Hilden Germany). All transfections were performed using lipofectamine 3000 (Invitrogen) for $6 \mathrm{~h}$ followed by medium refreshment and cells were further incubated for $48 \mathrm{~h}$. During this incubation time, cells were treated with $50 \mu \mathrm{M}$ I3C or $50 \mathrm{ng} / \mathrm{ml}$ LPS for $4 \mathrm{~h}$.

\section{Animal experiments}

All in vivo experiments were performed with 8-10-weekold BALB/CJ mice of both sexes. The animals were kept in an air-conditioned environment with 12-h light and dark cycle and had full access to water and food ad 
libitum. All experimental procedures complied with the ARVO Statement for the Use of Animals in Ophthalmic and Vision Research. The animal protocols were approved by the government office of animal welfare in North Rhine-Westphalia (Germany) (reference number 81-02.04.2019.A092). The mice received intraperitoneal injections of I3C at a dose of $15 \mathrm{mg} / \mathrm{kg}$ body weight, dissolved in DMSO or DMSO alone as vehicle control, starting 1 day before the light exposure and then once daily for the remaining days. BALB/CJ mice were darkadapted for $16 \mathrm{~h}$ before light exposure. Pupil dilation was performed with $2.5 \%$ phenylephrine and $0.5 \%$ tropicamide under dim red light before the mice were exposed to bright white light (15,000 lux) for $1 \mathrm{~h}$. After light exposure, the animals were kept in dark-reared conditions overnight and then maintained under normal light conditions (12-h light and dark cycle) for the remaining experimental period.

\section{Immunohistochemistry}

Eyes were enucleated and fixed with $4 \%$ paraformaldehyde (ROTI ${ }^{\circ}$ Histofix, Carl-Roth; Germany) for $2 \mathrm{~h}$ at room temperature. Retinal flat mounts were prepared and permeabilized overnight (5\% Triton X-100, 5\% Tween-20 in PBS). The flat mounts were incubated with BLOTTO (1\% milk powder, $0.01 \%$ Triton X-100 in PBS) for $1 \mathrm{~h}$ to block nonspecific antigen binding. Subsequently, retinal flat mounts were incubated with primary antibody (rabbit anti-Iba1, dilution 1:1000, FUJIFILM Wako Chemicals; Neuss, Germany) overnight at $4{ }^{\circ} \mathrm{C}$. After washing steps, the retinal flat mounts were incubated with secondary antibody (goat anti-rabbit AlexaFlour 488 (green) A11008, Life Technologies) for $1 \mathrm{~h}$ at room temperature. After washing steps, retinal flat mounts were mounted on a microscopic slide and embedded with fluorescence mounting medium (VECTAS HIELD $^{\circ}$ HardSet $^{\text {Tw }}$ Antifade Mounting Medium H-1400, Vector Laboratories; Burlingame, USA). Images were taken with a Zeiss Imager M.2 equipped with Apotome.2 (Carl Zeiss; Germany).

For immunohistochemical analyses of cryosections, the eyes were enucleated and fixed with $4 \%$ paraformaldehyde (ROTI ${ }^{\circ}$ Histofix, Carl-Roth; Germany) for $2 \mathrm{~h}$ at room temperature. Whole eyes were then incubated with 30\% sucrose overnight and embedded in optimal cutting temperature (OCT) compound, shock frozen on dry ice and then stored at $-20^{\circ} \mathrm{C}$. Ten-micrometer sections were cut with a cryostat (Leica CM $3050 \mathrm{~S}$, Leica biosystem; Wetzlar, Germany). Sections were rehydrated with phosphate-buffered saline (PBS) and blocked with BLOTTO (1\% milk powder and 0.3\% Triton X-100 in PBS) followed by overnight incubation with primary antibody (rabbit anti-Iba1, dilution is 1:500 in BLOTTO,
FUJIFILM Wako Chemicals; Neuss, Germany) at $4{ }^{\circ} \mathrm{C}$. After washing, sections were incubated with secondary antibody (goat anti-rabbit AlexaFlour 488 (green), dilution is 1:1000 in PBS, A11008, Life Technologies) for $1 \mathrm{~h}$ at room temperature. After washing steps, the sections were mounted with Flouromount and counterstained with Dapi (ThermoFisher Scientific; Waltham, USA). Images were taken with a Zeiss Imager M.2 equipped with Apotome.2 (Carl Zeiss; Germany).

\section{Optical coherence tomography (OCT)}

For OCT, mice were anesthetized by intraperitoneal injection of ketamine hydrochloride $(100 \mathrm{mg} / \mathrm{kg}$ body weight, Ketavet; Zoetis) and xylazine hydrochloride $(10 \mathrm{mg} / \mathrm{kg}$ body weight, Rompun; Bayer HealthCare) diluted in 0.9\% sodium chloride. The pupils of the mice were dilated using $2.5 \%$ phenylephrine and $0.5 \%$ tropicamide before OCT. Spectral-domain optical coherence tomography (SD-OCT) was performed on both eyes with a Spectralis ${ }^{\mathrm{mm}}$ HRA/OCT device (Heidelberg Engineering) to quantify the retinal thickness using the Heidelberg Eye Explorer Software with circular ring scans (circle diameter 3 and 6 $\mathrm{mm}$ ), centered around the optic nerve head.

\section{Statistical analysis}

Data were analyzed using GraphPad Prism version 7 (GraphPad Software Inc., San Diego, CA). All data were analyzed using analysis of variance (one-way ANOVA) and Dunnett's multiple comparison test. $p<0.05$ was considered as statistically significant.

\section{Results}

I3C reduces pro-inflammatory and enhances anti-oxidant gene expression in BV-2 cells

We first examined whether treatment with the AhR ligand $\mathrm{I} 3 \mathrm{C}$ has an effect on a selected set of proinflammatory markers in microglia-like BV-2 cells. The cells were pre-treated with $50 \mu \mathrm{M}$ I3C for $4 \mathrm{~h}$ and then further stimulated with $50 \mathrm{ng} / \mathrm{ml}$ LPS for additional $4 \mathrm{~h}$. LPS stimulation-induced mRNA levels for inducible NO-synthase (i-NOS) (Fig. 1a), interleukin-1 beta (IL-1ß) (Fig. 1b), NOD-, LRR-, and pyrin domain-containing protein 3 (NLRP3) (Fig. 1c), interleukin-6 (IL-6) (Fig. 1d), and C-C motif chemokine ligand 2 (CCL2) (Fig. 1e) and co-treatment with I3C significantly dampened expression of these markers. Since AhR ligands are known to exert anti-oxidant effects, we also measured mRNAs for NADPH dehydrogenase quinone 1 (NQO1) (Fig. 1f), heme oxygenase 1 HMOX1 (Fig. 1g), and catalase 1 (CAT1) (Fig. 1h). For each of these three genes, I3C enhanced mRNA expression levels (Fig. 1f-h). We then aimed to confirm these data using Western blots. These 

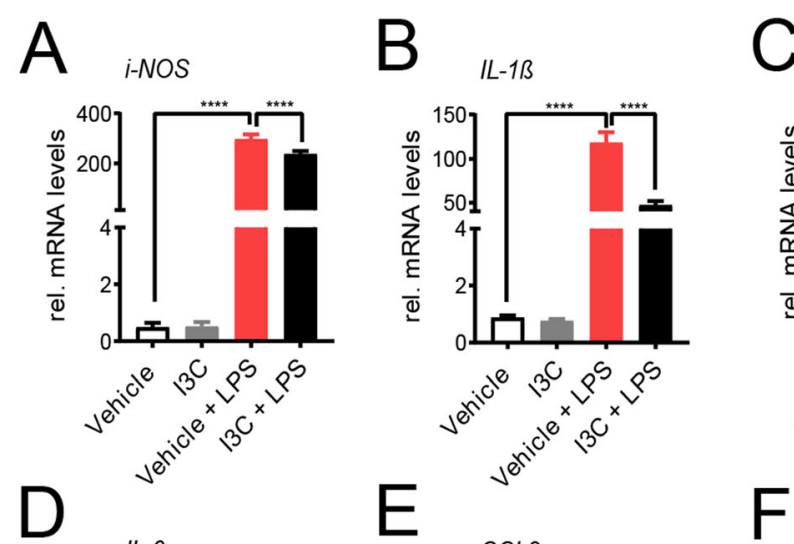

$\mathrm{C}_{\text {NLRP3 }}$
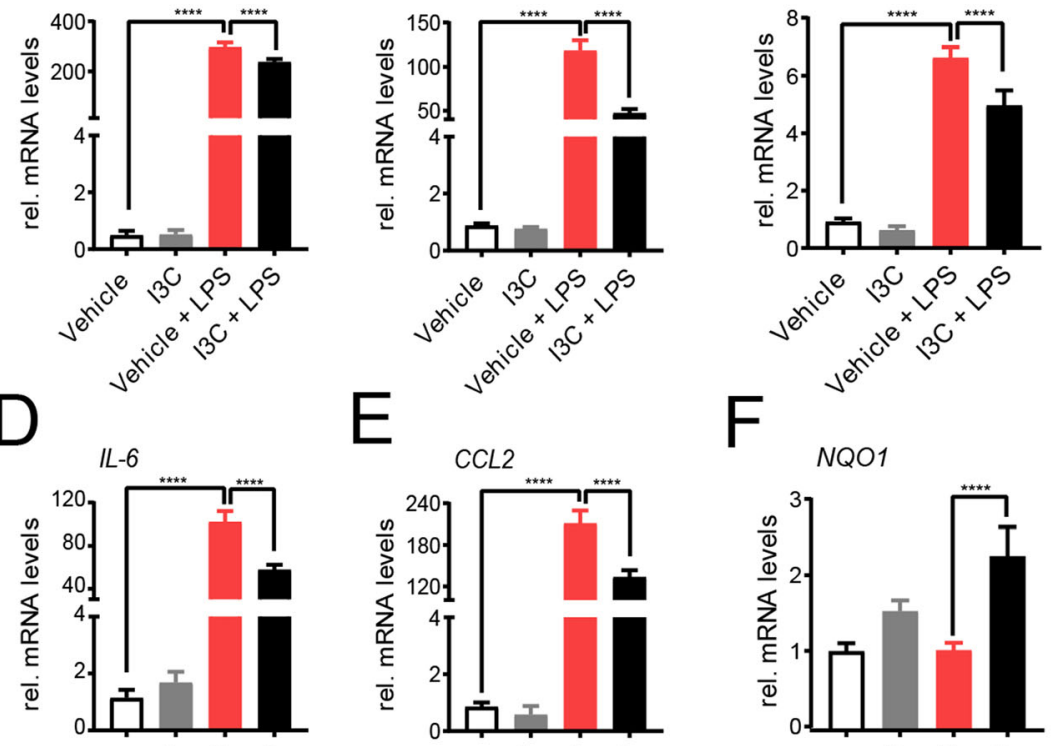

$\mathrm{E}$
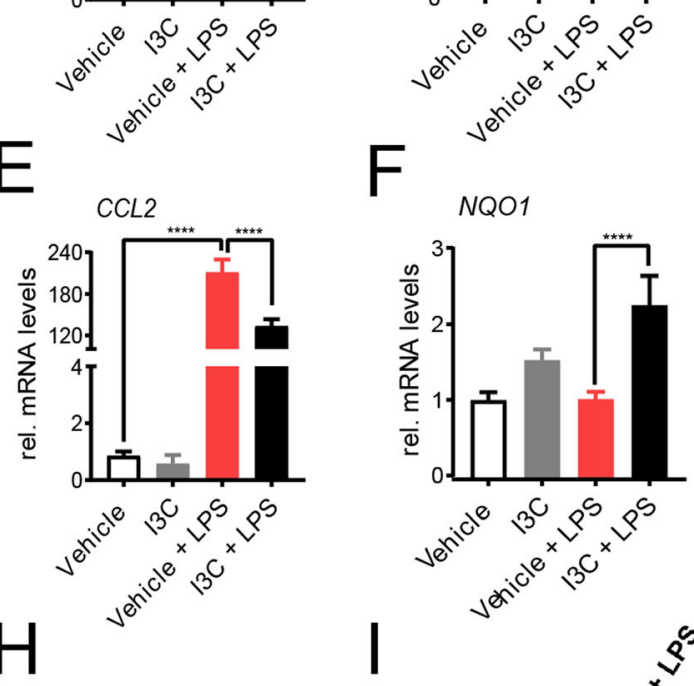

$G$

HMOX 1

CAT1
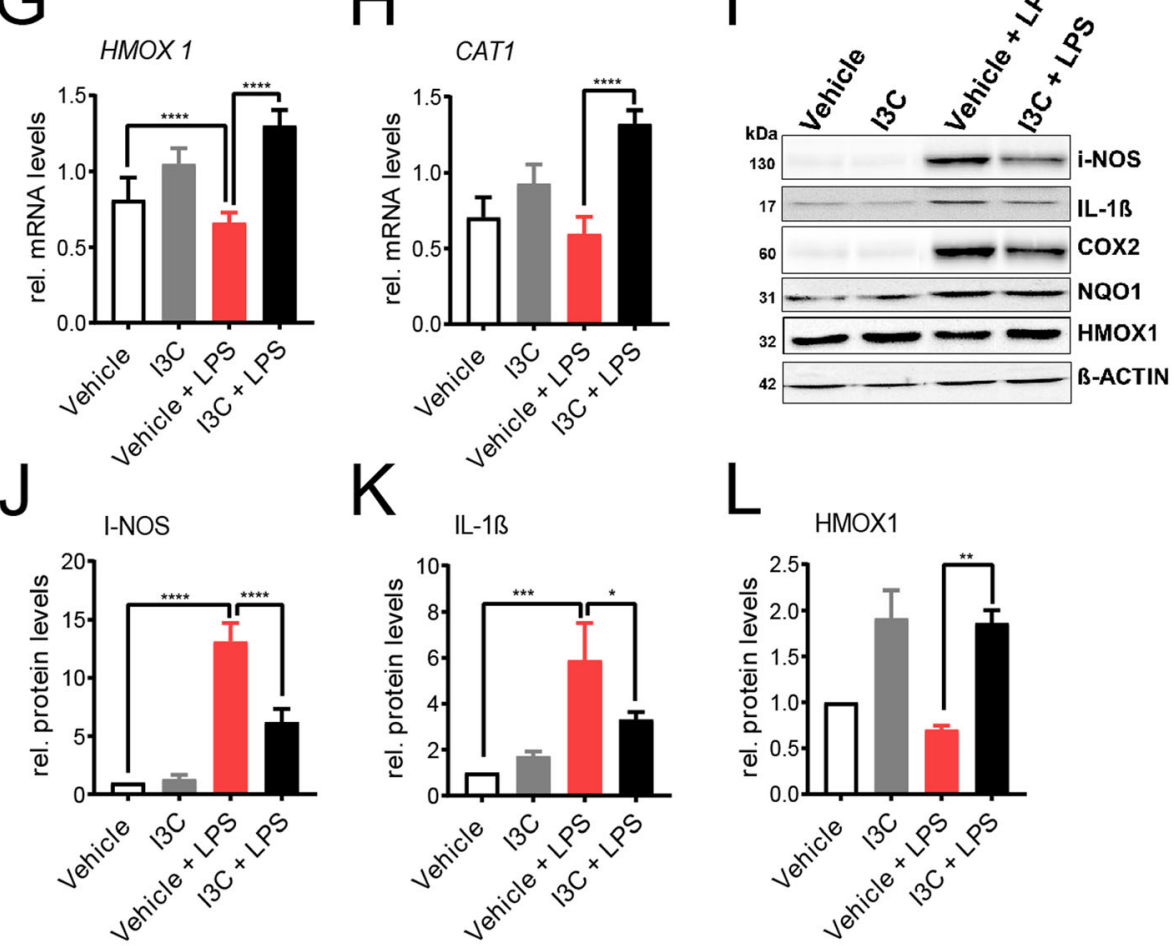

Fig. 1 Effects of IBC on pro-inflammatory and anti-oxidant mRNA and protein levels. a-h BV-2 microglia cells were treated with $50 \mu \mathrm{M} I 3 C$ or DMSO as a vehicle for $4 \mathrm{~h}$ followed by $50 \mathrm{ng} / \mathrm{ml}$ LPS for $4 \mathrm{~h}$. After $8 \mathrm{~h}$, mRNA expression levels of $i-N O S \mathbf{a}, I L-1 B \mathbf{b}, N L R P 3 \mathbf{c}, I L-6 \mathbf{d}, C C L 2$ e, NQO1 f HMOX1 $\mathbf{g}$, and CAT1 $\mathbf{h}$ were analyzed by real-time PCR. i Western blots show i-NOS, IL-1B, COX2, NQO1, HMOX1, and B-ACTIN protein levels as a loading control. Mean relative protein levels are shown for $\mathrm{i}-\mathrm{NOS} \mathbf{j}$, IL-1ß $\mathbf{k}$, and HMOX $1 \mathbf{I}$. Data show mean \pm SEM out of three independent experiments for mRNA expression levels ( $n=3$ /group, measured in triplicates). For Western blot, three independent experiments were performed. ${ }^{*} p<0.05,{ }^{* *} p<0.01,{ }^{* * *} p<0.001,{ }^{* * * *} p<0.0001$ 
experiments revealed that the LPS-induced expression of i-NOS, IL $1 ß$, and cyclooxygenase 2 (COX2) was also reduced by $\mathrm{I} 3 \mathrm{C}$ on the protein level, whereas HMOX1 was increased and NQO1 was unchanged (Fig. 1i-l). Taken together, the treatments with I3C reduced LPS-mediated pro-inflammatory markers and enhances antioxidant gene expression in BV-2 cells.

\section{I3C reduces LPS-induced nitric oxide secretion, caspase $3 /$}

\section{7activity, and phagocytosis}

We next analyzed three functional parameters of microglia activity, namely, NO secretion, neurotoxicity, and phagocytosis. In accordance with our mRNA and protein data on i-NOS expression, I3C also significantly reduced the LPS-triggered NO secretion from BV-2 cells (Fig. 2a).
To test the influence of I3C on microglia neurotoxicity, the cone-derived 661W photoreceptor cell line was used and the cells were incubated for $48 \mathrm{~h}$ with conditioned media from BV-2 microglia and caspaserelated apoptotic cell death was analyzed. The $661 \mathrm{~W}$ cells cultured in LPS-activated microglia supernatants showed significantly higher caspase $3 / 7$ activity as compared to the vehicle (Fig. 2b). This increase in caspase $3 / 7$ activity was significantly diminished by I3C treatment (Fig. 2b).

To study the effects of I3C on phagocytosis, BV-2 cells were treated with I3C and LPS for $4 \mathrm{~h}$ and then latex polystyrene beads were added for another $4 \mathrm{~h}$. LPS strongly induced the number of phagocytosed beads compared to vehicle (Fig. 2c-d), whereas I3C treatment significantly reduced the number of phagocytosed beads (Fig. 2c-d).

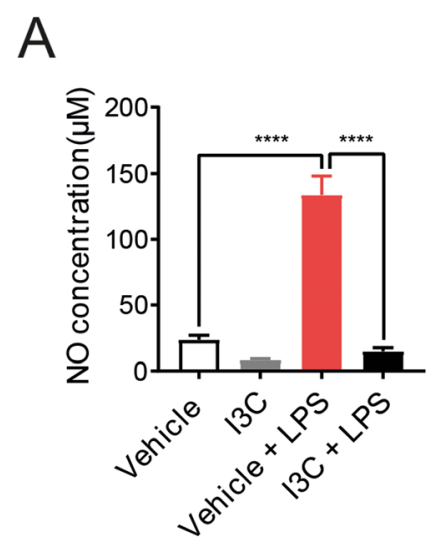

\section{$\mathrm{B}$}

C
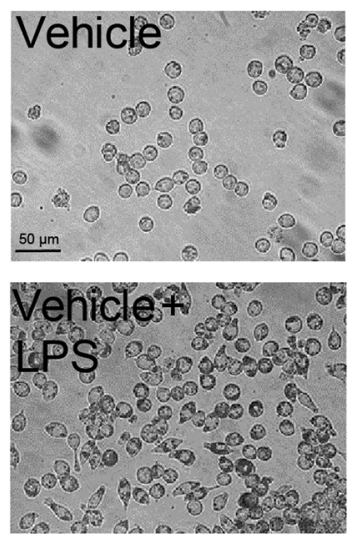
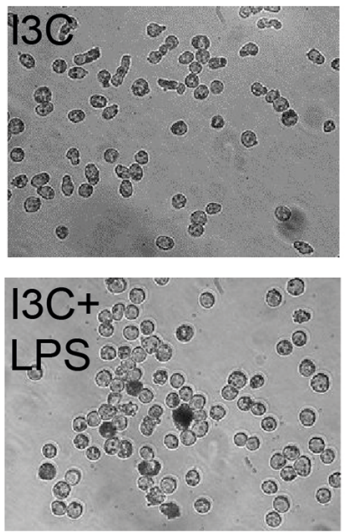

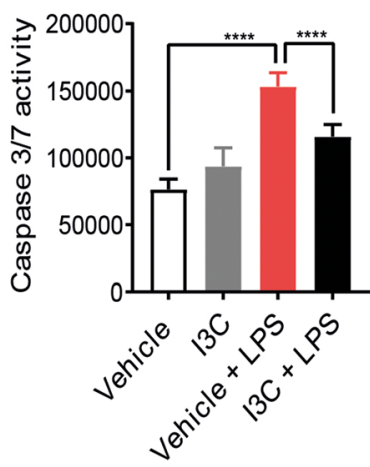

$\mathrm{D}$

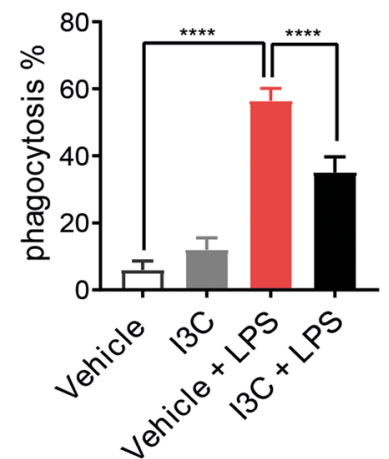

Fig. 2 Effects of I3C on LPS-induced nitric oxide production, caspase 3/7 levels, and phagocytosis. BV-2 microglia were treated with $50 \mu \mathrm{M}$ I3C or DMSO as a vehicle for $4 \mathrm{~h}$ followed by $50 \mathrm{ng} / \mathrm{ml}$ LPS. a Twenty-four hours later, cell culture supernatants were taken for measuring the concentration of nitric oxide by Griess assay. $\mathbf{b}$ To determine the neurotoxicity, cell culture supernatant from BV-2 microglia were transferred to $661 \mathrm{~W}$ photoreceptor cells. After $48 \mathrm{~h}$ of incubation of $661 \mathrm{~W}$ cells with conditioned medium from BV-2 cells, caspase 3/7 activity was measured to determine apoptotic cell death. c Representative images of microglia incubated with latex beads for $4 \mathrm{~h}$ after treatments. $\mathbf{d}$ Relative phagocytosis of BV-2 cells was calculated by counting the cells having more than 10 latex beads. Data show mean \pm SEM out of three independent experiments ( $n=3$ /group, measured in triplicates) with ${ }^{* * *} p<0.0001$ 
I3C reduces LPS-induced migration and induces filopodia formation in BV-2 cells

To study the influence of I3C on microglia migration, wound-healing scratch assays were conducted in BV-2 cells. LPS induced the migration of BV-2 microglia cells into the scratch (Fig. 3a), and I3C effectively blocked this migration response (Fig. 3a). The morphology of microglia is another hallmark of activation and hence we stained the F-actin cytoskeleton with phalloidin-TRITC in the different culture conditions. LPS clearly triggered a change in morphology from ramified to an amoeboid shape (Fig. 3b). Incubations in the presence of $\mathrm{I} 3 \mathrm{C}$ clearly transformed the BV-2 cells to a highly ramified phenotype with most cells containing long filopodia (Fig. 3b). Taken together, I3C reduces LPS-induced migration and induces filopodia formation in BV-2 microglia cells.

The AhR pathway is involved in the in vitro effects of $I 3 C$ on pro-inflammatory gene expression

To further investigate the AhR pathway in modulation of pro-inflammatory gene expression, siRNA-mediated knockdown of AhR was performed in BV-2 microglia. The cells were transfected with AhR siRNA or non-targeting negative
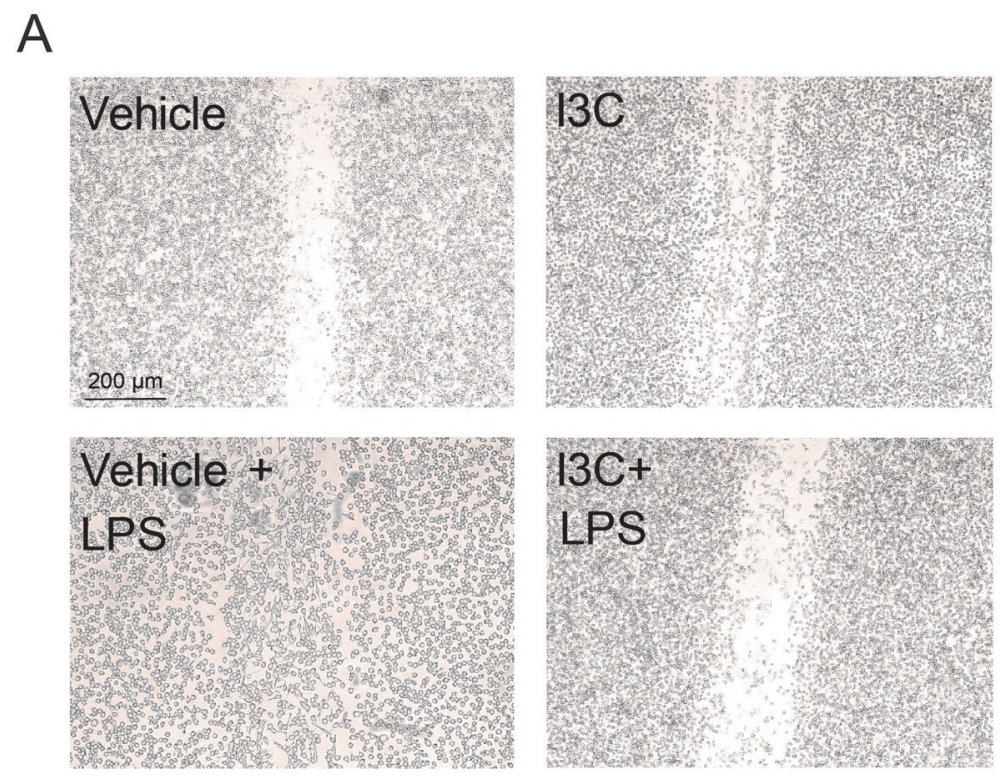

B
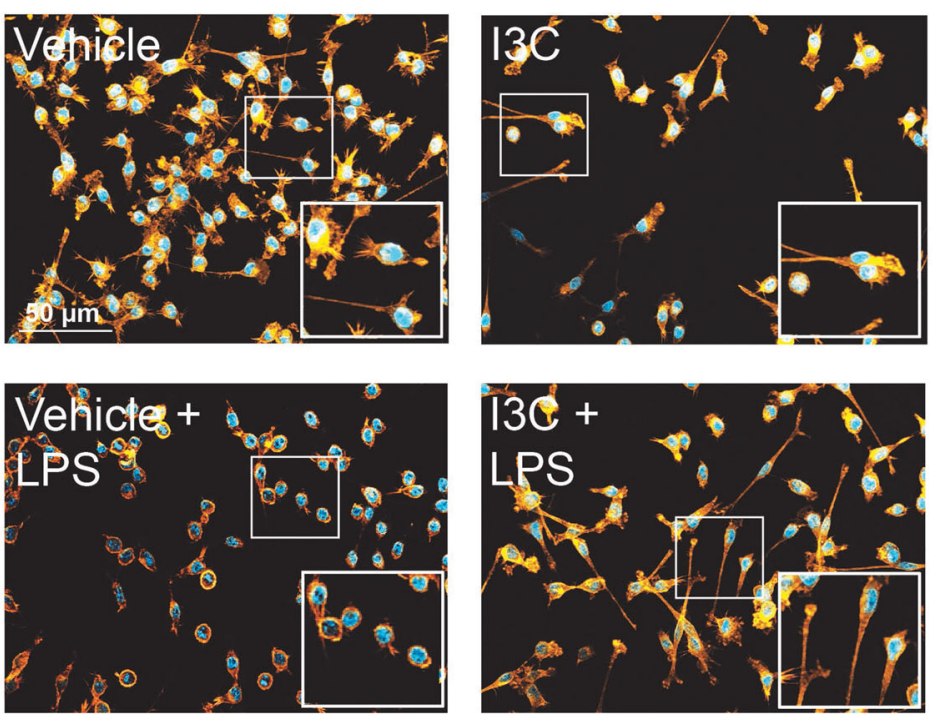

Fig. 3 Effects of I3C on LPS-induced migration and morphology of BV-2 microglia. BV-2 microglia cells were treated with $50 \mu \mathrm{M}$ I3C or DMSO as a vehicle for $4 \mathrm{~h}$ followed by $50 \mathrm{ng} / \mathrm{ml}$ LPS after scratch with a pipette tip. a Representative images of microglia migration toward the scratch area after 8 h. b Representative images of the BV-2 cell morphology stained with phalloidin and DAPI. ( $n=3 /$ group, measured in triplicates) 
control siRNA. We detected that the mRNA level of AhR itself was significantly downregulated by AhR siRNA (Fig. 4a). Treatment of AhR siRNA-transfected cells with I3C plus LPS caused a relative increase in $i$-NOS (Fig. 4b), $I L-1 \beta$ (Fig. 4c), and NLRP3 (Fig. 4d) transcript levels compared to the siRNA negative control. In contrast, $I L-6$ mRNA expression levels were not changed in the presence of AhR siRNA (Fig. 4e). Thus, AhR knockdown partially prevented the previously detected anti-inflammatory effects of I3C on LPS-activated BV-2 cells.

\section{I3C treatment regulates pro-inflammatory and antioxidant genes in the light-damage model of murine retinal degeneration}

We next aimed at analyzing the effects of I3C in the murine retina subjected to an established light damage paradigm of retinal degeneration. Light-sensitive BALB/ cJ mice were dark-adapted for $16 \mathrm{~h}$ before the mice were exposed to white light with an intensity of 15,000 lux for $1 \mathrm{~h}$. The animals received intraperitoneal injections of $15 \mathrm{mg} / \mathrm{kg}$ I3C or DMSO as a vehicle, the day before the light exposure, and then once daily for the remaining 3 days (Fig. 5a).

Four days after light exposure, retinal mRNA expression levels of the pro-inflammatory markers $i$-NOS (Fig. 5b), $I L-1 \beta$ (Fig. 5c), NLRP3 (Fig. 5d), IL-6 (Fig. 5e), and CCL2 (Fig. 5f). Whereas relative expression of these genes changed in light exposed and vehicle-treated retinas, I3C treatment significantly reversed these effects (Fig. 5b-f).

We next verified these mRNA expression differences on the protein level and further included two antioxidant proteins, NQO1 and HMOX1, that are mainly regulated on protein level. The effects on retinal CCL2 protein expression were verified using ELISA, which showed that I3C reduced light-induced CCL2 secretion (Fig. 5g). Western blots further revealed that $\mathrm{I} 3 \mathrm{C}$ also reduced light-damage induced i-NOS, IL-1ß, and p-NFKBp65 protein levels in the retina (Fig. $5 \mathrm{~h}-\mathrm{j}$ ), whereas protein levels for the antioxidant genes NQO1 and HMOX1 were upregulated in I3C-treated animals (Fig. 5h, k).

\section{I3C prevents microglia reactivity in the light-damaged retina}

To assess the effects on retinal microglia in vivo, retinal flat mounts of light-challenged and I3C-treated mice were stained with the marker IBA1. We found that retinas of untreated mice show no microglia in the subretinal (SR) space (Fig. 6a), whereas vehicle + light-treated animals showed abundant amoeboid microglia in this area (Fig. 6b). Thus, accumulation of amoeboid microglia in the SR space was prevented by I3C treatment (Fig. 6c, d). The outer plexiform layer (OPL) of untreated control animals showed mainly ramified microglia (Fig. 6e). In contrast, vehicletreated and light-exposed mice had less ramifications and showed a more amoeboid morphology (Fig. 6f). Again, these signs of microglia reactivity were prevented by I3C therapy (Fig. 6g).

We also analyzed the localization of IBA1-positive cells in retinal layers using cryosections. In untreated animals, mainly ramified microglia were detected in both plexiform layers (Fig. 6h). In contrast, amoeboid microglia were present in the ONL of light-damage and vehicle-treated mice (Fig. 6i). Notably, I3C nearly fully prevented this light-induced amoeboid microglia accumulation (Fig. 6j). Furthermore, the DAPI staining of cryosections of light-damage and vehicle-treated mice indicated a significant cell loss in the ONL, which was prevented by I3C (Fig. 6h-k).

\section{I3C preserves retinal thickness after light exposure}

Finally, we analyzed the effects of I3C on retinal degeneration 4 days after acute light exposure. In vivo imaging with optical coherence tomography (OCT) showed strong retinal thinning and nearly complete loss of the ONL in light-exposed mice that received vehicle treatment compared to animals not subjected to light damage (Fig. 7a, b). Treatment with I3C clearly prevented this retinal degeneration (Fig. 7c), as confirmed by repeated quantitative analyses of the central retinal thickness within $3 \mathrm{~mm}$ and $6 \mathrm{~mm}$ ring scan areas (Fig. 7d, e).

\section{Discussion}

Recent studies showed that AhR is important for the maintenance of photoreceptor and RPE homeostasis [13, 15]. To our knowledge, we here show for the first time that AhR also regulates microglia homeostasis in the degenerating retina and that its natural ligand $\mathrm{I} 3 \mathrm{C}$ protects from acute light damage, a model system that mimics certain aspects of human retinal degeneration.

We started our study with in vitro experiments using BV-2 microglia treated with LPS and I3C. BV-2 is an established murine microglia cell line [16]. Despite its limitation as an immortalized cell type, BV-2 cells represent a good alternative for primary microglia as gene expression profiling showed that LPS-treated BV-2 cells shared $90 \%$ of genes with primary microglia [18-20]. We found here that I3C potently reduced LPS-triggered gene and protein expression of well-established proinflammatory transcripts $[17,21,22]$. Conversely, I3C induced anti-oxidant gene expression, which is consistent with previous findings that $\mathrm{I} 3 \mathrm{C}$ has antioxidant activity [23]. Our data are in line with previous findings that I3C can block LPS-induced IL-1 $\beta$, IL-6, and $\mathrm{NO}$ in RAW264.7 macrophage cells [24]. Previous findings also showed that I3C mediates apoptosis in different cancer cells [25-27]. However, our results indicate that I3C can 


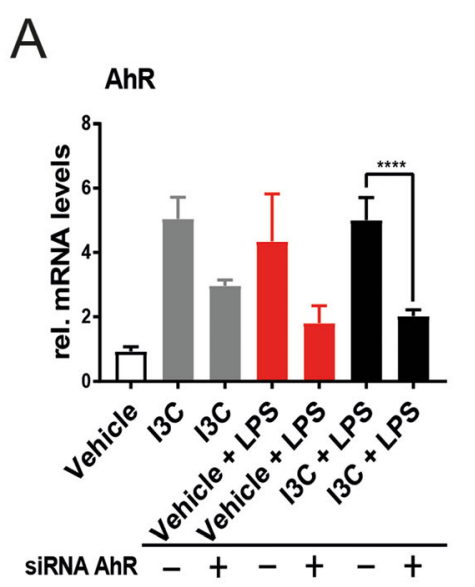

B

C

IL-1ß
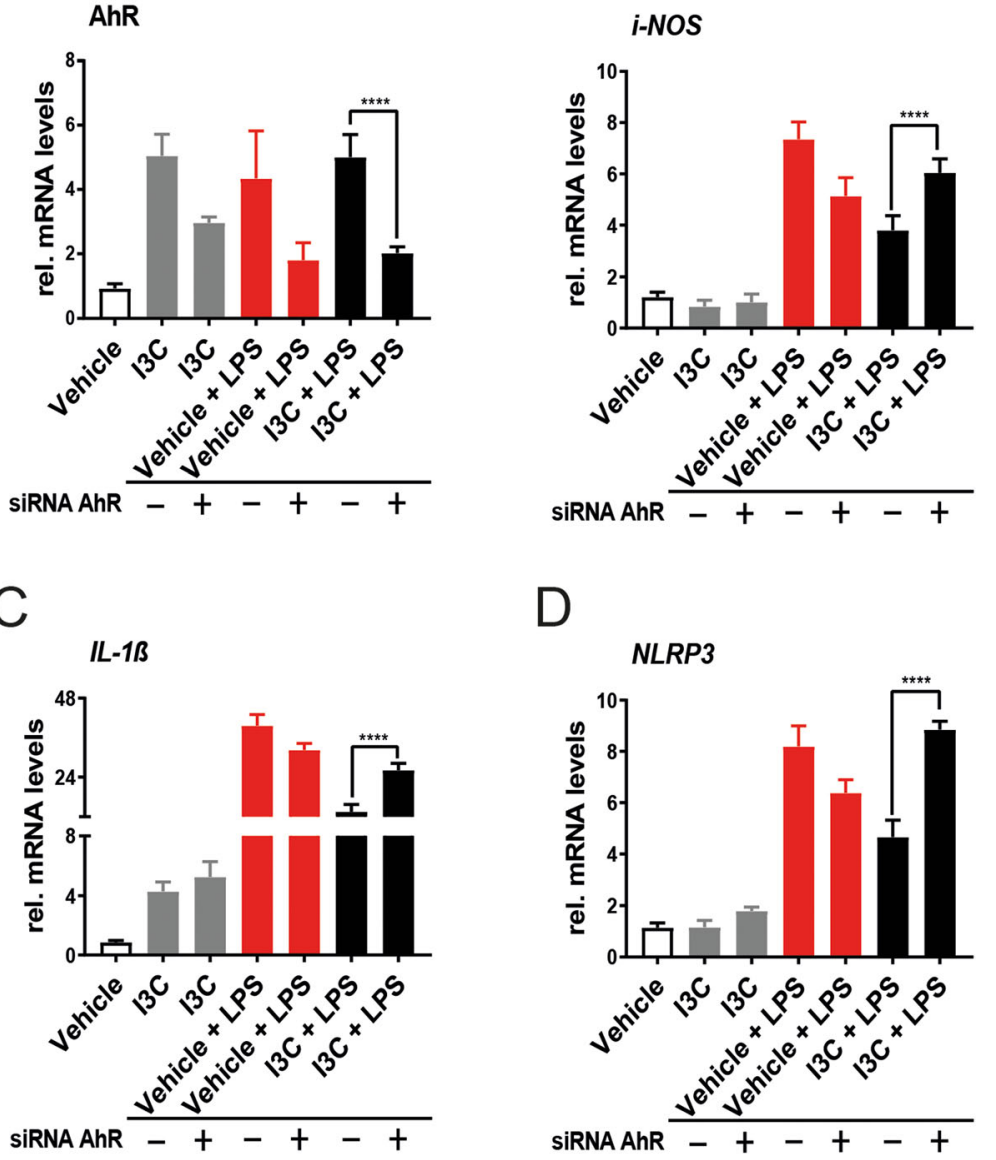

E

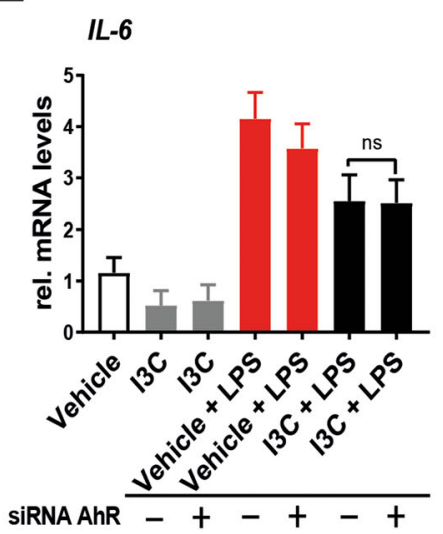

Fig. 4 Effects of AhR knockdown on pro-inflammatory markers in BV-2 microglia. Cells were transfected with AhR-siRNA for $6 \mathrm{~h}$ followed by treatment with I3C and LPS. a-e mRNA expression levels of AhR $\mathbf{a}, i-N O S \mathbf{b}, I L-1 / 3 \mathbf{c}, N L R P 3 \mathbf{d}$, and IL-6 e were analyzed by real-time PCR. Data show mean \pm SEM out of three independent experiments ( $n=3 /$ group, measured in triplicates) with ${ }^{* * *} p<0.0001$

reduce neurotoxic effects of activated microglia on 661W photoreceptor cells. Despite the limitation that $661 \mathrm{~W}$ cells are derived from a retinal tumor and express mainly cone-specific markers [28], the cells have been documented as reliable in vitro model to study molecular pathways of neuronal apoptosis [29, 30].

In this study, LPS induced the phagocytosis of latex beads in BV-2 cells, consistent with previous findings 
A

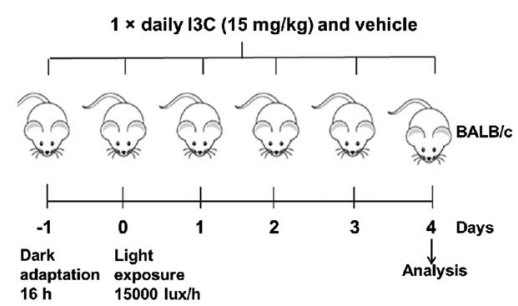

D

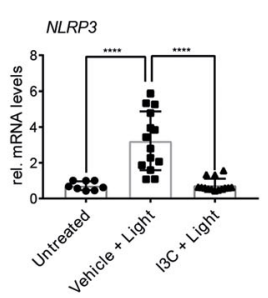

E

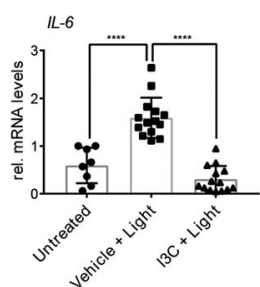

$\mathrm{H}$

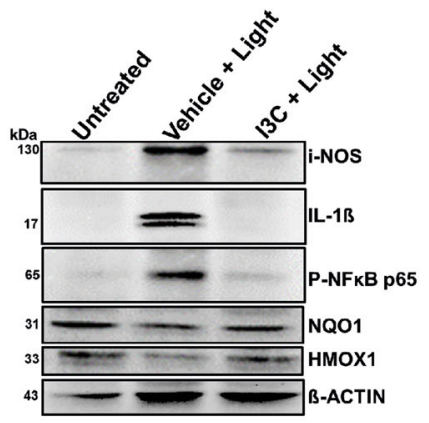

K

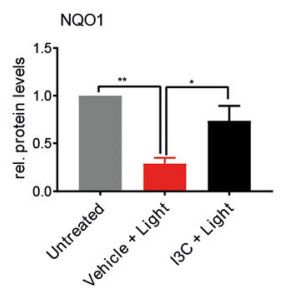

B

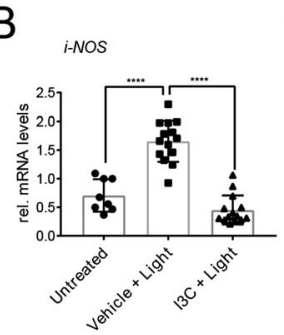

C

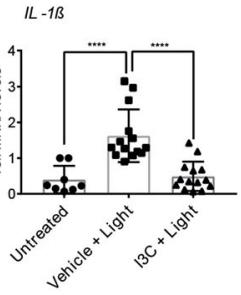

F

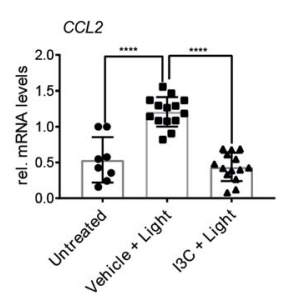

G

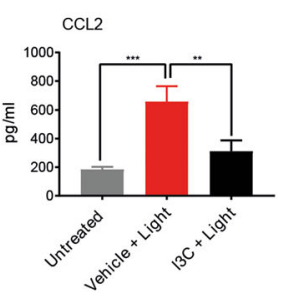

I

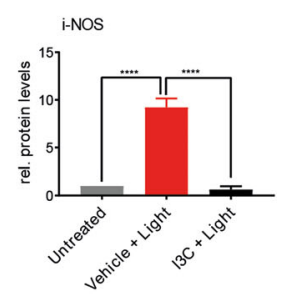

J

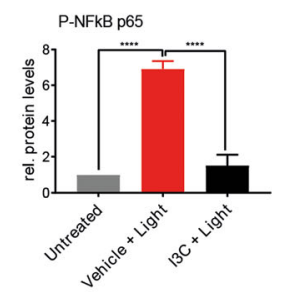

Fig. 5 Effects of $I 3 C$ on mRNA and protein levels in light-challenged BALB/CJ mice. a Schematic overview of experimental design. Eight to ten-weekold BALB/CJ mice of both sexes were used. Mice were dark-adapted for $16 \mathrm{~h}$ before the mice were exposed to white light with an intensity 15,000 lux for $1 \mathrm{~h}$. The animals received intraperitoneal injections of $15 \mathrm{mg} / \mathrm{kg} \mathrm{ISC}$ or vehicle (DMSO), 1 day before the light exposure and once daily for the remaining 3 days. Four days after the light exposure, b-f mRNA expression levels of $i-N O S \mathbf{b}, I L-1 B \mathbf{c}, N L R P 3 \mathbf{d}, I L-6 \mathbf{e}$, and $C C L 2 \mathbf{f}$, were analyzed by realtime PCR. Four days after the light exposure, retinal lysates were extracted to perform ELISA of CCL2 $\mathbf{g}$ and Western blots $\mathbf{h}$ detecting i-NOS, IL- 1B, pNFKB65, NQO1, and HMOX1 protein levels. Beta-actin served as loading control. Relative protein levels for i-NOS i, p-NFkBp65 $\mathbf{j}$, and NQO1 k were determined by densitometry. Data show mean \pm SEM out of three independent experiments for mRNA expression levels (untreated $n=8$ retinas, vehicle + light $n=14$ retinas, light +13 C treatment $n=14$ retinas, where each dot represents one retina). For Western blots and ELISA three independent experiments were performed (one retina per group) with ${ }^{*} p<0.05,{ }^{* *} p<0.01,{ }^{* *} p<0.001$, and ${ }^{* * *} p<0.0001$

$[20,21,31]$. We also found that I3C significantly reduced this phagocytic capacity. Phagocytosis assays with latex beads have clear limitations and may only serve as a proxy for the real situation in neuronal tissue. Clearly, in vivo phagocytosis requires multiple cellular interactions and complex molecular signaling events in microglia that are absent in cell culture phagocytosis assays [32, 33]. Nevertheless, our previous data showed a good correlation of microglial phagocytosis rates measured with latex beads and apoptotic photoreceptor debris [21]. Our study further revealed that I3C reduced LPS-induced migration and reversed the typical LPS-triggered amoeboid 


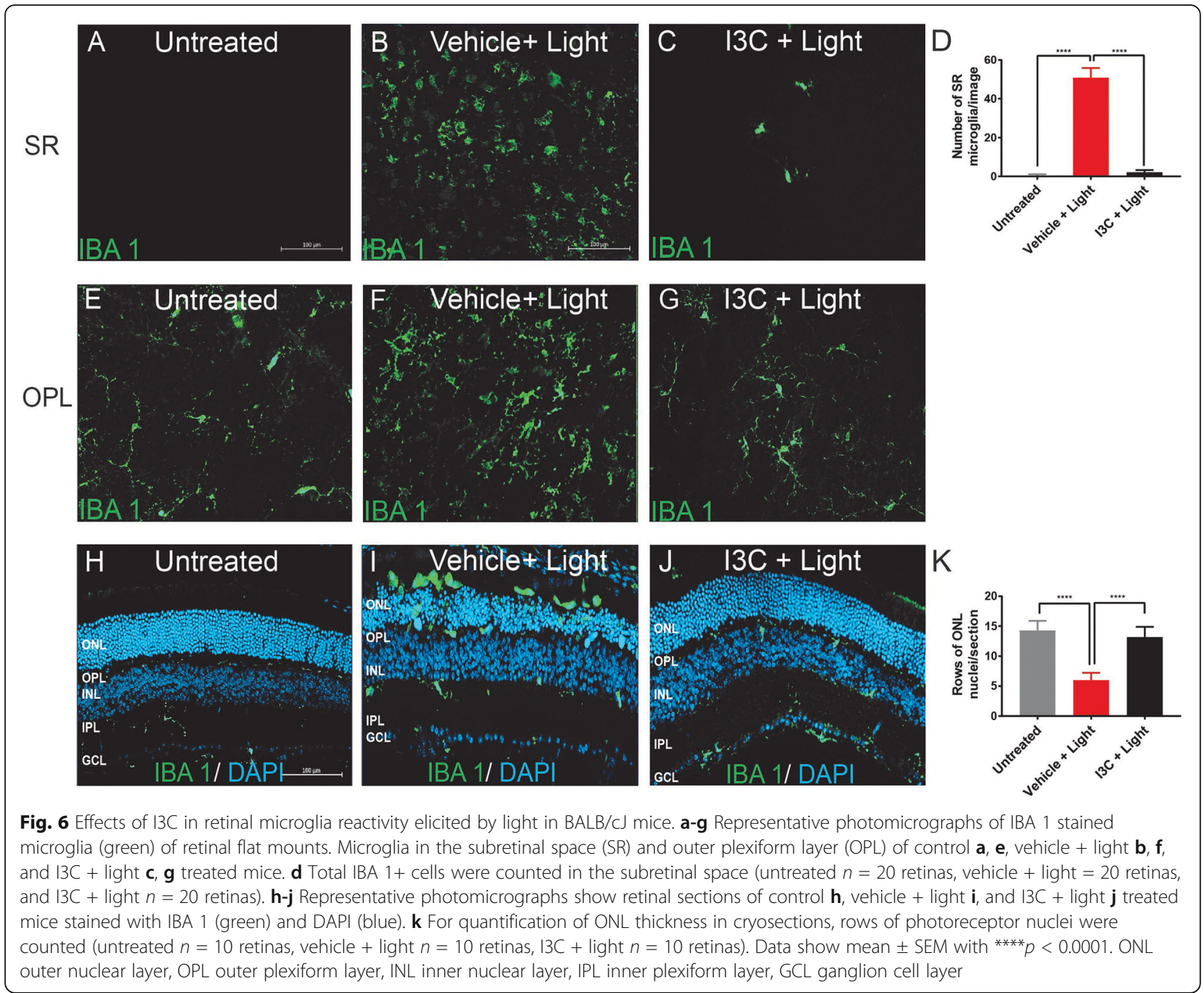

phenotype of BV-2 microglia [21, 34]. These data support the finding that $A h R$ is a master regulator of cellular phagocytosis, migration, and morphology [35-37].

We also investigated the specificity of $\mathrm{I} 3 \mathrm{C}$ using siRNA-mediated knockdown of AhR in BV-2 microglia. These data revealed that knockdown of AhR prevents the I3C-mediated decrease of i-NOS, IL-1ß, and NLRP3. However, we found that AhR knockdown did not alter IL-6 mRNA. This suggests that AhR is not directly involved in LPS-induced IL-6 gene regulation. In accordance with our results, AhR activation downregulated NLRP3 and IL-1ß mRNA levels in peritoneal macrophages and siRNA-mediated knockdown of AhR reversed this effect [38].

The in vitro data of I3C effects lead us to the analysis of microglia in a white-light-damage paradigm of retinal degeneration. Light damage is a convenient and reproducible method for inducing synchronized photoreceptor damage [39]. However, differences in the effects of neuroprotective agents between light damage and genetic mouse models have been documented [40]. Therefore, effects seen in this model cannot be transferred to retinal degenerative diseases in general. Our results clearly showed that I3C inhibited light-induced proinflammatory gene expression in vivo as $\mathrm{i}-\mathrm{NOS}$, IL- $1 ß$, NLRP3, and IL-6 transcripts were significantly diminished in I3C-treated animals. These data are in agreement with other neuroinflammatory and ocular disorders. Thus, I3C prevented ischemic reperfusion-induced inflammation and improved neurobehavioral symptoms in a cerebral ischemic stroke model [41, 42]. AhR agonists also reversed pro-inflammatory gene expression in experimental autoimmune uveitis [11]. Here, we found that I3C prevented light-induced CCL2 expression in the retina. Upregulation of CCL2 in light-exposed animals has been documented by others before $[43,44]$. We further showed that I3C reduced 

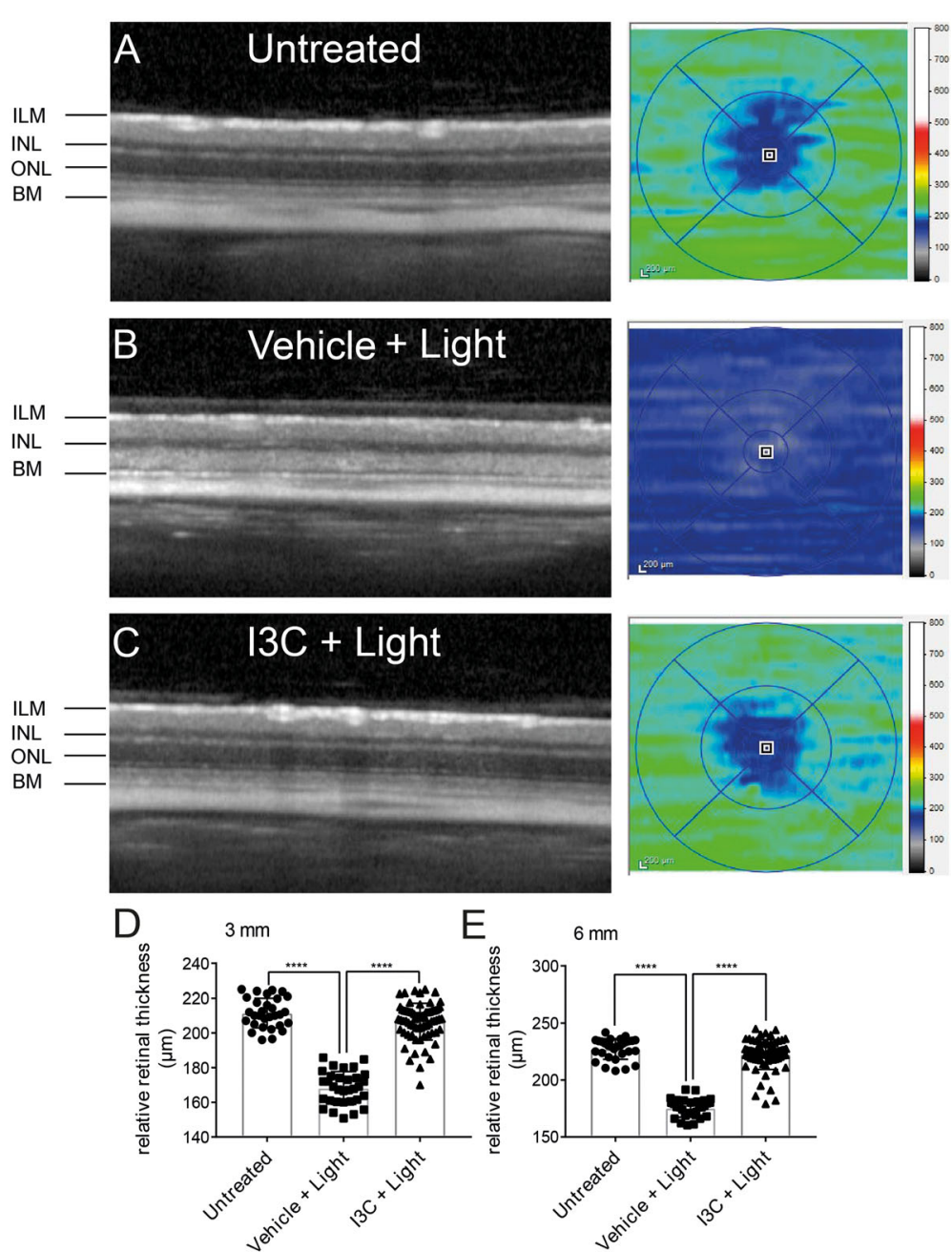

Fig. 7 Effects of IBC on retinal thickness in light-damaged BALB/CJ mice. a-c Four days after light damage, SD-OCT was performed to analyze the changes in retinal thickness displaying heat maps of $\mathbf{a}$ untreated, $\mathbf{b}$ vehicle + light, and $\mathbf{c}$ I3C + light-treated mice. $\mathbf{d}$-e Relative retinal thickness $(\mu \mathrm{m})$ in $3 \mathrm{~mm}$ and $6 \mathrm{~mm}$ areas were calculated using the SD-OCT software, where one data point represents the average thickness of the central retina. Data show mean \pm SEM (untreated $n=30$ eyes, vehicle + light $n=32$ eyes, light $+13 C$ treatment $n=70$ eyes). ${ }^{* * *} p<0.0001$

light-induced IL-1ß and p-NFkBp65 levels in the retina. Likewise, it has been shown that AhR activation limits IL$1 ß$ and NFkB in microglia $[38,45,46]$.

We also noticed that $\mathrm{I} 3 \mathrm{C}$ upregulated $\mathrm{NQO} 1$ and HMOX1 protein levels in the retina of light-treated animals. Consistent with our data, 2AI, a synthetic AhR ligand enhanced the antioxidant battery of genes in the retina [15]. AhR is obviously necessary for normal immune physiology as AhR-deficient mice display a highly inflammatory phenotype with high levels of oxidative stress in the retina [47, 48].

Here, we used the AhR ligand I3C in a retinal light damage model and showed previously unknown effects on microglia reactivity. We have selected I3C as it is a known natural anti-inflammatory agent that can act on neuronal tissues. For example, it reduced clonidineinduced neurotoxicity in rats, and enhanced antioxidant levels in experimental models of Parkinson's disease
[49, 50]. I3C is rapidly absorbed and distributed in the blood, liver, kidney, lung, heart, and brain [51]. $\mathrm{AhR}$ is expressed by various retinal cell types including microglia, RPE, photoreceptors, and retinal ganglion cells $[15,52,53]$. Previous studies highlighted the potential role of AhR in retinal neuroprotection without focusing on microglia $[12,13,15]$. Together with these published data, our findings suggest that AhR activation in the damaged retina may have a dual beneficial effect on RPE as well as microglia homeostasis.

\section{Conclusions}

Our results highlight an important function of $A h R$ and its ligand $\mathrm{I} 3 \mathrm{C}$ in regulating retinal microglia homeostasis. The observed anti-inflammatory and neuroprotective effects suggest that AhR may be a potential therapeutic target for retinal degeneration. 


\section{Abbreviations}

2Al: 2,2'-aminophenyl indole; AhR: Aryl hydrocarbon receptor; AMD: Agerelated macular degeneration; CAT1: Catalase 1; CCL2: C-C motif chemokine ligand 2; COX2: Cyclooxygenase 2; FCS: Fetal calf serum; HMOX1: Heme oxygenase 1; i-NOS: Inducible NO synthase; I3C: Indole-3-carbinol; IL6: Interleukin-6; IPL: Inner plexiform layer; LPS: Lipopolysaccharide; NLRP3: NOD-, LRR-, and pyrin domain-containing protein 3; NO: Nitric oxide; NQO1: NADPH dehydrogenase quinone 1; OPL: Outer plexiform layer; qRTPCR: Quantitative real-time PCR; SD-OCT: Spectral domain-optical coherence tomography; siRNA: Small interfering RNA; SR: Subretinal space

\section{Acknowledgements}

We thank Eva Scheiffert for her technical assistance in animal experiments.

\section{Authors' contributions}

AK participated in the design of experiments, conducted the experiments, analyzed and interpreted the data, wrote the first manuscript draft, and assembled the figures. TL developed the study concept and all experimental designs, supervised the project, and wrote and revised the manuscript. The authors read and approved the final manuscript

\section{Funding}

This work was supported by the Hans and Marlies Stock foundation and the Pro Retina Foundation. Open Access funding enabled and organized by Projekt DEAL.

\section{Availability of data and materials}

The data supporting the findings of this study are available from the corresponding author upon request.

\section{Ethics approval and consent to participate}

All animal experiments were approved by the government office of animal welfare in North Rhine-Westphalia (Germany) (reference number 8102.04.2019.A092).

\section{Consent for publication}

Not applicable.

\section{Competing interests}

The authors declare no competing interests.

Received: 28 July 2020 Accepted: 14 October 2020

Published online: 03 November 2020

\section{References}

1. Akhtar-Schäfer I, Wang L, Krohne TU, Xu H, Langmann T. Modulation of three key innate immune pathways for the most common retinal degenerative diseases. EMBO Mol Med. 2018;10:e8259.

2. Rashid K, Akhtar-Schaefer I, Langmann T. Microglia in retinal degeneration. Front Immunol. 2019;10:1975.

3. Madore C, Yin Z, Leibowitz J, Butovsky O. Microglia, lifestyle stress, and neurodegeneration. Immunity. 2020;52:222-40.

4. Karlstetter M, Scholz R, Rutar M, Wong WT, Provis JM, Langmann T. Retinal microglia: just bystander or target for therapy? Progress in Retinal and Eye Research. 2015;45:30-57

5. Hao N, Whitelaw ML. The emerging roles of AhR in physiology and immunity. Biochem Pharmacol. 2013;86:561-70.

6. Larigot L, Juricek L, Dairou J, Coumoul X. AhR signaling pathways and regulatory functions. Biochimie Open. 2018;7:1-9.

7. Bravo-Ferrer I, Cuartero MI, Medina V, Ahedo-Quero D, Peña-Martinez C, Pérez-Ruíz A, et al. Lack of the aryl hydrocarbon receptor accelerates aging in mice. FASEB J. 2019;33:12644-54.

8. Brinkmann V, Ale-Agha N, Haendeler J, Ventura N. The aryl hydrocarbon receptor (AhR) in the aging process: another puzzling role for this highly conserved transcription factor. Front Physiol. 2020;10:1561.

9. Stockinger B, Di Meglio P, Gialitakis M, Duarte JH. The aryl hydrocarbon receptor: multitasking in the immune system. Ann Rev Immunol. 2014;32: 403-32.

10. Shinde R, McGaha TL. The aryl hydrocarbon receptor: connecting immunity to the microenvironment. Trends Immunol. 2018;39:1005-20.
11. Huang $Y$, He J, Liang H, Hu K, Jiang S, Yang L, et al. Aryl hydrocarbon receptor regulates apoptosis and inflammation in a murine model of experimental autoimmune uveitis. Front Immunol. 2018;9:1713.

12. Hu P, Herrmann R, Bednar A, Saloupis P, Dwyer MA, Yang P, et al. Aryl hydrocarbon receptor deficiency causes dysregulated cellular matrix metabolism and age-related macular degeneration-like pathology. Proc Natl Acad Sci U S A. 2013;110:E4069-78.

13. Kim SY, Chang YS, Chang YS, Kim JW, Brooks M, Chew EY, et al. Deletion of aryl hydrocarbon receptor AHR in mice leads to subretinal accumulation of microglia and RPE atrophy. Investig Ophthalmol Vis Sci. 2014;55:6031-40

14. Choudhary M, Kazmin D, Hu P, Thomas RS, McDonnell DP, Malek G. Aryl hydrocarbon receptor knock-out exacerbates choroidal neovascularization via multiple pathogenic pathways. J Pathol. 2015;235:101-12.

15. Gutierrez MA, Davis SS, Rosko A, Nguyen SM, Mitchell KP, Mateen S, et al. A novel AhR ligand, $2 \mathrm{Al}$, protects the retina from environmental stress. Sci Rep. 2016;6:29025

16. Blasi E, Barluzzi R, Bocchini V, Mazzolla R, Bistoni F. Immortalization of murine microglial cells by a v-raf/v-myc carrying retrovirus. J Neuroimmunol. 1990;27:229-237.

17. Scholz R, Sobotka M, Caramoy A, Stempfl T, Moehle C, Langmann T. Minocycline counter-regulates pro-inflammatory microglia responses in the retina and protects from degeneration. J Neuroinflammation. 2015;12:209.

18. Stansley B, Post J, Hensley K. A comparative review of cell culture systems for the study of microglial biology in Alzheimer's disease. J Neuroinflammation. 2012;9:115.

19. Henn A, Lund S, Hedtjärn M, Schrattenholz A, Pörzgen P, Leist M. The suitability of BV2 cells as alternative model system for primary microglia cultures or for animal experiments examining brain inflammation. Altex. 2009;26:83-94.

20. Majerova P, Zilkova M, Kazmerova Z, Kovac A, Paholikova K, Kovacech B, et al. Microglia display modest phagocytic capacity for extracellular tau oligomers. J Neuroinflammation. 2014;11:161.

21. Karlstetter M, Nothdurfter C, Aslanidis A, Moeller K, Horn F, Scholz R, et al. Translocator protein $(18 \mathrm{kDa})(\mathrm{TSPO})$ is expressed in reactive retinal microglia and modulates microglial inflammation and phagocytosis. J Neuroinflammation. 2014;11:3.

22. Orihuela R, McPherson CA, Harry GJ. Microglial M1/M2 polarization and metabolic states. Br J Pharmacol. 2016:173:649-65.

23. Lin H, Gao X, Chen G, Sun J, Chu J, Jing K, et al. Indole-3-carbinol as inhibitors of glucocorticoid-induced apoptosis in osteoblastic cells through blocking ROS-mediated Nrf2 pathway. Biochem Biophys Res Commun. 2015:460:422-7.

24. Jiang J, Kang TB, Shim DW, Oh NH, Kim TJ, Lee KH. Indole-3-carbinol inhibits LPS-induced inflammatory response by blocking TRIF-dependent signaling pathway in macrophages. Food Chem Toxicol. 2013;57:256-61.

25. Vorontsova JE, Cherezov RO, Kuzin BA, Simonova OB. Aryl-hydrocarbon receptor as a potential target for anticancer therapy. Biochem Suppl Ser B Biomed Chem. 2019;13:36-54.

26. Karimabad MN, Mahmoodi M, Jafarzadeh A, Darekordi A, Hajizadeh MR, Hassanshahi G. Molecular targets, anti-cancer properties and potency of synthetic indole-3-carbinol derivatives. Mini-Rev Med Chem. 2018:19:540-54.

27. Wang ML, Shih CK, Chang HP, Chen YH. Antiangiogenic activity of indole-3carbinol in endothelial cells stimulated with activated macrophages. Food Chem. 2012;134:811-20

28. Tan E, Ding XQ, Saadi A, Agarwal N, Naash MI, Al-Ubaidi MR. Expression of cone-photoreceptor-specific antigens in a cell line derived from retinal tumors in transgenic mice. Investig Ophthalmol Vis Sci. 2004;45:764-8.

29. Wheway G, Nazlamova L, Turner D, Cross S. 661W photoreceptor cell line as a cell model for studying retinal ciliopathies. Front Genet. 2019;10:308.

30. Sayyad Z, Sirohi K, Radha V, Swarup G. 661 W is a retinal ganglion precursorlike cell line in which glaucoma-associated optineurin mutants induce cell death selectively. Sci Rep. 2017;7:1-13.

31. Wiedemann J, Rashid K, Langmann T. Resveratrol induces dynamic changes to the microglia transcriptome, inhibiting inflammatory pathways and protecting against microglia-mediated photoreceptor apoptosis. Biochem Biophys Res Commun. 2018;501:239-45.

32. Nomura K, Vilalta A, Allendorf DH, Hornik TC, Brown GC. Activated microglia desialylate and phagocytose cells via neuraminidase, galectin-3, and mer tyrosine kinase. J Immunol. 2017;198:4792-801.

33. Galloway DA, Phillips AEM, Owen DRJ, Moore CS. Phagocytosis in the brain: homeostasis and disease. Front Immunol. 2019;10:790. 
34. Aslanidis A, Karlstetter M, Scholz R, Fauser S, Neumann H, Fried C, et al. Activated microglia/macrophage whey acidic protein (AMWAP) inhibits NFKB signaling and induces a neuroprotective phenotype in microglia. Neuroinflammation. 2015;12:77.

35. Lu HF, Tung WL, Yang JS, Huang FM, Lee CS, Huang YP, et al. In vitro suppression of growth of murine WEHI-3 leukemia cells and in vivo promotion of phagocytosis in a leukemia mice model by indole-3-carbinol. J Agric Food Chem. 2012;60:7634-43.

36. Rico-Leo EM, Alvarez-Barrientos A, Fernandez-Salguero PM. Dioxin receptor expression inhibits basal and transforming growth factor $\beta$-induced epithelial-to-mesenchymal transition. J Biol Chem. 2013;288:7841-56.

37. Josyula N, Andersen ME, Kaminski NE, Dere E, Zacharewski TR, Bhattacharya S. Gene co-regulation and co-expression in the aryl hydrocarbon receptormediated transcriptional regulatory network in the mouse liver. Arch Toxicol. 2020;94:113-26.

38. Huai W, Zhao R, Song H, Zhao J, Zhang L, Zhang L, et al. Aryl hydrocarbon receptor negatively regulates NLRP3 inflammasome activity by inhibiting NLRP3 transcription. Nat Commun. 2014,5:4738.

39. Wenzel A, Grimm C, Samardzija M, Remé CE. Molecular mechanisms of light-induced photoreceptor apoptosis and neuroprotection for retinal degeneration. Progress in Retinal and Eye Research. 2005;24:275-306.

40. Grimm C, Wenzel A, Stanescu D, Samardzija M, Hotop S, Groszer M, et al. Constitutive overexpression of human erythropoietin protects the mouse retina against induced but not inherited retinal degeneration. J Neurosci. 2004;24:5651-8.

41. Ampofo E, Lachnitt N, Rudzitis-Auth J, Schmitt BM, Menger MD, Laschke MW. Indole-3-carbinol is a potent inhibitor of ischemia-reperfusion-induced inflammation. J Surg Res. 2017;215:34-46.

42. Paliwal P, Chauhan G, Gautam D, Dash D, Patne SCU, Krishnamurthy S. Indole3-carbinol improves neurobehavioral symptoms in a cerebral ischemic stroke model. Naunyn Schmiedebergs Arch Pharmacol. 2018;391:613-25.

43. Rutar M, Natoli R, Valter K, Provis JM. Early focal expression of the chemokine C 12 by Müller cells during exposure to damage-inducing bright continuous light. Investig Ophthalmol Vis Sci. 2011;52:2379-88.

44. Rutar M, Natoli R, Provis JM. Small interfering RNA-mediated suppression of Ccl2 in Müller cells attenuates microglial recruitment and photoreceptor death following retinal degeneration. J Neuroinflammation. 2012;9:221.

45. Rothhammer V, Borucki DM, Tjon EC, Takenaka MC, Chao CC, ArduraFabregat A, et al. Microglial control of astrocytes in response to microbial metabolites. Nature. 2018;557:724-8.

46. Crunkhorn S. Autoimmune disease: aryl hydrocarbon receptor suppresses inflammation. Nat Rev Drug Discov. 2018;17:470.

47. Higgins PJ. Balancing AhR-dependent pro-oxidant and Nrf2-responsive antioxidant pathways in age-related retinopathy: is SERPINE1 expression a therapeutic target in disease onset and progression? J Mol Genet Med. 2015:8:101.

48. Perepechaeva ML, Grishanova AY, Rudnitskaya EA, Kolosova NG. The mitochondria-targeted antioxidant SkQ1 downregulates aryl hydrocarbon receptor-dependent genes in the retina of OXYS rats with AMD-like retinopathy. J Ophthalmol. 2014;2014:530943.

49. El-Naga RN, Ahmed HI, Abd Al Haleem EN. Effects of indole-3-carbinol on clonidine-induced neurotoxicity in rats: impact on oxidative stress, inflammation, apoptosis and monoamine levels. Neurotoxicology. 2014;44: 48-57.

50. Saini N, Akhtar A, Chauhan M, Dhingra N, Pilkhwal Sah S. Protective effect of indole-3-carbinol, an NF-KB inhibitor in experimental paradigm of Parkinson's disease: In silico and in vivo studies. Brain Behav Immun. 2020; 90:108-37.

51. Anderton MJ, Manson MM, Verschoyle RD, Gescher A, Lamb JH, Farmer PB, et al. Pharmacokinetics and tissue disposition of indole-3-carbinol and its acid condensation products after oral administration to mice. Clin Cancer Res. 2004;10:5233-41.

52. Juricek L, Carcaud J, Pelhaitre A, Riday TT, Chevallier A, Lanzini J, et al. AhRdeficiency as a cause of demyelinating disease and inflammation. Sci Rep. 2017;7:9794.

53. Rothhammer V, Quintana FJ. The aryl hydrocarbon receptor: an environmental sensor integrating immune responses in health and disease. Nature Reviews Immunology. 2019;19:184-97.

\section{Publisher's Note}

Springer Nature remains neutral with regard to jurisdictional claims in published maps and institutional affiliations.

\section{Ready to submit your research? Choose BMC and benefit from:}

- fast, convenient online submission

- thorough peer review by experienced researchers in your field

- rapid publication on acceptance

- support for research data, including large and complex data types

- gold Open Access which fosters wider collaboration and increased citations

- maximum visibility for your research: over $100 \mathrm{M}$ website views per year

At BMC, research is always in progress.

Learn more biomedcentral.com/submissions 